\title{
Cidades, corpos medicalizados e o biocapital: o mercado da saúde
}

\author{
Flávia Cristina Silveira Lemos, ${ }^{I}$ Dolores Galindo, ${ }^{I I}$ \\ Renata Vilela Rodrigues, ${ }^{I I}$ Katia Faria de Aguiar ${ }^{I I I,} \star \star$ \\ ${ }^{I}$ Universidade Federal do Pará, Belém, PA, Brasil, "II Universidade Federal de Mato Grosso, Cuiabá, MT, Brasil \\ III Universidade Federal Fluminense, Niterói, RJ, Brasil
}

\begin{abstract}
Resumo
Este artigo tem o objetivo de colocar em interrogação as práticas de medicalização das cidades e dos corpos por meio do governo da vida, em uma sociedade neoliberal que tornou as populações capitais e os espaços das cidades lugares de empreendimento. Pretende pensar os processos de subjetivação fazendo uma crítica ao investimento das cidades e dos corpos enquanto biocapitais, assegurados por um mercado crescente, em nome da saúde e segurança. Com os estudos de Michel Foucault e algumas de suas ferramentas, efetuou-se uma história breve da medicalização das cidades e dos corpos bem como dos seus efeitos na produção de subjetividades, no contemporâneo.
\end{abstract}

Palavras-chave: biocapital; cidades; corpos; medicalização; biopolítica.

\section{Cities, bodies medicalized and the biocapital: the market health}

\begin{abstract}
This article aims to put in question the medicalization practices of cities and bodies through the government of life in a neoliberal society that became the capital populations and areas of the city enterprise spaces. Want to think the subjectivity processes making a critical investment of cities and bodies as biocapitais rely on a growing market, in the name of health and safety. With the studies of Michel Foucault and some of its tools made a brief history of the medicalization of cities and bodies. Also well as their effects on the production of subjectivities, in the contemporary.
\end{abstract}

Keywords: biocapital; towns; bodies; medicalization; biopolitics.

\section{Introdução}

Neste artigo, abordamos o acontecimento cidades e corpos medicalizados por uma rede bioeconômica, descrevendo e analisando suas zonas cinzentas, suas linhas constitutivas e a materialização da regulação da saúde, dos corpos e do espaço pelo biocapital. Enfatizamos o papel constitutivo do cálculo econômico de custo e benefício, na gestão pela medicalização enquanto racionalidade que se sustenta pelo biocapital e opera por ele, em uma economia política neoliberal. Estamos interessados, neste texto, em pensar as estratégias biopolíticas centradas na capitalização dos espaços e dos corpos, regulados enquanto empreendimentos neoliberais.

Problematizamos a maneira como questões específicas da vida e da população foram postas no interior de tecnologias de governo que regem a conduta humana e performaram subjetivações cada vez mais precaucionárias, temerosas e caracterizadas pelo empresariamento de si e dos outros. Pensar a medicalização do espaço é relevante para as psicologias, em diferentes facetas, por exemplo, em termos dos efeitos, os quais forjam subjetividades medicalizadas e medicalizantes.

Vertentes das Psicologias têm repensando as teorias e práticas subjetivas, considerando a subjetividade como uma figura histórica, social e política e propondo falar em "produção de subjetividade" como uma alternativa à problematização de identidades, que se esgota numa exaustão ao idêntico (PRADO FILHO; MARTINS, 2007).

\footnotetext{
^Endereço para correspondência: Universidade Federal Fluminense, Centro de Estudos Gerais. Rua Prof. Marcos Waldemar de Freitas Reis, s/no Bloco O, 3 andar - São Domingos. CEP: 24210201 - Niterói, RJ - Brasil. E-mail: flavazeve do@bol.com.br, dolorescristinagomesgalindo@gmail.com, renatinha.vilela@ gmail.com, katiafaguiar@uol.com.br
}

Como psicólogas, indagamos as naturalizações dos jogos de verdades que acionam processos de subjetivação característicos do mercado biomédico e médicopsicológico das populações e das cidades, em especial, pelo mercado e religião da saúde, hoje. Discutimos a capitalização da vida para problematizar as formas de subjetivações que emergem na comercialização dos corpos e na privatização das cidades, na atualidade.

Mais especificamente, examinamos as estratégias biopolíticas, na contemporaneidade, as quais impulsionam uma capitalização da vida por segmentos empresariais, na esfera de sua gestão do espaço das cidades e dos corpos. Discorremos sobre os modos de subjetivação que emergem nesse cenário na imanência do cuidado em saúde, pautados na lógica do temor frente aos futuros riscos, de acordo com os cálculos liberais de segurança.

\section{Cidades medicalizadas e empreendedoras: segurança e biocapital}

A biopolítica, no século XXI, abre-se para dimensões nas quais as biotecnologias arregimentam novas formas de vida social e participação política (NOVAS, 2006; RABINOW, 1999). Política e ciência se cruzam com as biomedicinas, com o objetivo de proporcionar saúde e longevidade à população. Dessa maneira, a biopolítica atual está dirigida às exigências globais dos mercados internacionais, ao mesmo tempo em que está embutida nas políticas locais que regulam e reformatam os corpos e cidades, na direção de torná-los mais saudáveis e resistentes à depredação do tempo.

Gómez (2004), ao analisar o contexto biopolítico latino-americano, mostra que a condição de gerência da vida, na América Latina, ao se propor ao 
comprometimento com o corpo e com o dever social, está ainda diretamente relacionada com as formas de governo praticadas desde o século XIX. Em lugares como o Brasil, por exemplo, é comum visualizarmos uma forma de guerrilha que se tornou mal disfarçada e cotidiana, restituída nas desigualdades econômicas e sociais, nos eventos cada vez mais menos incomuns de violência urbana, que se relacionam frequentemente a ações prepotentes de instituições oficiais encarregadas pela segurança (CASTIEL, 2010).

Entretanto, vale apontar que, em meio a essas estratégias de segurança pelo controle da circulação dos corpos, nas cidades (GÓMEZ, 2004), em países denominados "em desenvolvimento" ou "emergentes", entre os quais o Brasil, problemáticas biopolíticas direcionadas às políticas públicas merecem nossas atenções, como, por exemplo, as zonas de espera dos aeroportos, a escassez de transportes públicos, negligências nos hospitais e nas escolas.

A circulação no espaço é alvo de mapeamento e programação político-econômica, a partir dos dispositivos de segurança (FOUCAULT, 2008a), da disciplina ordenadora dos corpos no espaço, da medicalização das cidades e dos corpos dos pobres. O Estado é medicalizado em uma biocracia, uma ordem biopolítica e um biocapital, que emerge na segunda metade do século XIX e vai se ampliando, no último século (FOUCAULT, 1979).

A organização da política econômica em mercados da saúde, em uma verdadeira religião do controle biotecnológico das cidades e dos corpos, ganha intensa materialidade pela medicina social, que se estende por toda a sociedade, como racionalidade reducionista da complexidade da vida aos aspectos biomédicos.

Foucault (1979, 1988) salienta como ocorreu a medicalização da cidade pelas táticas biopolíticas e disciplinares, ao tratar das estratégicas higienistas de limpeza urbana e de organização disciplinar do espaço das cidades pela lógica urbanista, militar, biológica, demográfica, estatística, geográfica, política, jurídica e médico-psicológica. Higienizar espaços implicou realizar processos autoritários de medicalização, com a retirada de corpos classificados como indigentes e como refugos humanos dos centros urbanos para enviá-los a lugares de segregação, isolados.

No curso Nascimento da Biopolítica, Foucault (2008b) ressalta o aspecto de mercado, no cálculo de custo e benefício da relação entre liberdade e segurança, no governo da população nas cidades. Para ele, gerir riscos e perigos se tornou um mecanismo de modulação dessa relação nada simples de oferta de liberdade e de seu asseguramento protetivo. A paradoxal encomenda de lei e ordem traz a questão nada simples que apontamos acima, pois as democracias atuais, em contextos neoliberais, vivem esse impasse e o coloca em um âmbito de mercado de direitos, tais como o direito à saúde e à circulação na cidade, para consumir, comprar e vender, viajar, trabalhar, estudar, visitar lugares, se relacionar, transportar, se divertir e se cuidar.
Em Segurança, território e população, Foucault (2008a) já relatava que a polícia do cotidiano foi uma técnica instalada pelo Estado moderno para controlar os deslocamentos dos corpos na cidade e regular sua conduta, na biopolítica. Ainda destaca que a circulação no espaço se tornou uma das principais problemáticas do liberalismo e do uso dos higienismos normalizadores de condutas para operar a relação entre corpos e meio. Essa noção de meio surge com a visão entre biologia e cultura, em especial, em um darwinismo social, utilitarista e liberal, que transformava os circuitos em mercado e a saúde em uma religião da circulação supostamente segura.

Para assegurar o trânsito pela cidade, os corpos são encomendados à busca da saúde e estes demandam do Estado práticas de oferta da limpeza e da ordem urbana, como a redução das taxas de violência e o controle de epidemias, bem como reivindicam condições seguras de circular pelo espaço e de empreender, na cidade, negócios, lazeres, trabalhos, estudos, relações afetivas, exercícios físicos, acessos a serviços variados etc.

Foucault (2008a, 2008b) enfatiza que o neoliberalismo torna a governamentalidade um mercado da saúde e da cidade em nome da produção do dispositivo de segurança e que os países se tornam seguros, na medida em que conseguem garantir seguridade social aos que desejam consumir e empreender no espaço.

Nesse sentido, os processos de medicalização operam como estratégias da medicina social, acoplada aos saberes biotecnológicos, à geografia política, à economia neoliberal, à bioinformática, à gestão empresarial da vida e da circulação, um lugar relevante para que o mercado possa fazer viver e deixar morrer a população em nome da liberdade de regulamentação dos empreendimentos.

A revista Exame (MELHORES..., 2014) destaca que há cinco capitais brasileiras entre as melhores cidades do país para se empreender. O periódico pauta alguns critérios que nomeia como inovação, tecnologia e capital humano, como indicadores de mercado e do que chama qualidade de vida. Esse acontecimento é um analisador para problematizarmos o presente em que vivemos e de que modo uma gestão empresarial da cidade e das subjetividades ocorre pela saúde e pela economia política, no neoliberalismo.

Em nome do aumento de performances produtivas e marcadas pela perspectiva de segurança, corpos, subjetividades e cidades poderão ser medicalizados pelo reducionismo biotecnológico, biomédico, biopsicológico, da bioinformática, da biocracia, do biocapital, da bioeconomia, enfim, da biopolítica. Objetivar os circuitos urbanos e suas ligações com as zonas rurais e com estados, países e hemisférios significa analisar as circulações sendo tecidas por meio de lógicas securitárias, baseadas em saberes e poderes. A religião da saúde também é um mercado da mesma e traz, no conceito de qualidade de vida e empreendimento de bem-estar, um mote e marketing usado para negociar capitais variados, como o relacional, o humano, o social, o afetivo, o biológico, o ambiental e o psicológico. 
Por isso, Foucault (2008a, 2008b) assinala como a saúde e contextos denominados de riscos foram constituídos pelo deslocamento das pastorais cristãs em termos de cuidado para ser governamentalizado pelo Estado e pela sociedade, em nome da condução de condutas do povo/população sujeito de direitos/sujeito econômico empresário de si e dos outros - no neoliberalismo.

A higiene dos corpos e das cidades ganha pela educação em saúde preventiva um lugar diferenciado na gestão da vida e da população como direito, no Estado Democrático de Direito, governamentalizado, securitário e medicalizado. Foucault (1979) relata como para a cidade e os corpos foram medicalizados; primeiro: o Estado deveria ser medicalizado e se constituir como gestor da saúde, da vigilância dos espaços e de sua população. Após, medicalizar a gestão estatal, a cidade e os trabalhadores também seriam medicalizados, governados por normas e leis, relacionadas, à limpeza, ao arejamento, ao urbanismo, na vigilância em saúde, nas prevenções de doenças, em relação ao saneamento e alimentação, na construção das casas e avenidas, nos estímulos aos exercícios e regularidade da vacinação, etc.

\section{Subjetivações empresariais: a produção de vidas investimentos nas cidades empreendimentos}

Para Rose (2011a), o termo "subjetivação" designa um agenciamento heterogêneo de corpos, vocabulários, técnicas, inscrições e práticas pelos quais as pessoas passam a se relacionar como sujeitos de certo tipo (MILLER; ROSE, 2012). Contemporaneamente, as tecnologias políticas e econômicas de produção de subjetividades se desenvolvem com o apoio de diversos campos de conhecimento das ciências biológicas, médicas e sociais. As tecnologias de subjetivação podem ser concebidas em termos de interconexões, métodos e linhas de força complexas entre componentes heterogêneos que incitam, possibilitam e estabilizam relações particulares do indivíduo consigo mesmo, em locais específicos com a utilização de práticas de si, denominadas por alguns pesquisadores, tais como: bioascese e biossociabilidade (ORTEGA, 2008; SANT'ANNA, 2009; CÉSAR, 2009).

Essas práticas são culturas de si, ligadas ao consumo de tecnologias de saúde e de dietas, exercícios físicos, fármacos, compostos de vitaminas e proteínas, vestimentas, modos de vida variados, ligados a um empresariamento de si conforme regras prescritas por saberes e poderes, em nome da religião da saúde, da pastoral médico-psicológica e de um crescente mercado do bem-estar.

As maquinações, o ser-agenciado-junto com determinados instrumentos intelectuais e práticos, componentes, entidades e dispositivos que produzem certos tipos de ser humano, que territorializam, estratificam, fixam, organizam e tornam duráveis certas relações particulares que o ser humano pode verdadeiramente estabelecer consigo mesmo (ROSE, 2011a, p. 259).

Como figura do neoliberalismo, a subjetividade empreendedora de si é apresentada por Foucault (2008a) como homo economicus, constituído pelos atravessamentos da economia política, do sujeito de direitos, da gestão de riscos e da sociedade de controle. Nessa realidade, a vida mesma se torna objeto de investimentos e passa a figurar como estilo neoliberal de ser e pensar, de relacionar-se. Nesse empresariamento de si, a saúde preventiva aparece como mercado, e os corpos passam a ser cada vez mais moldados por uma variedade de biotecnologias. Evidenciam-se subjetivações que emergem em uma rede complexa de produção tecnobiológica. Nós nos tornamos parte de uma ampla negociação coletiva que envolve uma rede de produção capitalista de tipos de seres humanos e não/ humanos, de entidades e híbridos, de saúde e doença (WALDBY, 2002).

Os processos de subjetivação vão se constituindo por linhas técnicas e por biossociabilidades administradas e capitalizadas econômica e politicamente, em nome da sociedade de segurança (CASTIEL, 2011). De certa forma, ganhamos autonomia e liberdade, mas a autonomia para nos vigiarmos e a liberdade de nos tornarmos peritos, experts de nós mesmos, da nossa saúde, do nosso corpo (ORTEGA, 2004). A própria vida vai se tornando assunto na problematização do cotidiano e não mero objeto de investigação.

A vida em si mesma, ou própria vida (do original life itself) é uma terminologia criada por Franklin (2000), para se referir à forma como a comercialização da própria vida levanta indagações sobre a acumulação de capital, assim como a maneira como as pessoas têm tratado a vida, não mais como algo naturalizado, mas fabricado e comercializado pela racionalidade genética.

A autora explora o conceito de própria vida a partir da análise, da popularização do filme hollywoodiano Jurassic Park, no qual as novas tecnologias genéticas são narradas e animadas como produção e consumo, permitindo visualizar como entidades geneticamente modificadas são nascidas, criadas, construídas e, principalmente, imaginadas pelas pessoas. Com a análise do filme, Franklin (2000) gera um conjunto de perspectivas sobre as imagens propiciadas pelas indústrias genéticas que têm modulado o modo como nos relacionamos com os artefatos de inovação tecnológica e, com isso, com nossa própria vida e, em especial, entre os pais e filhos (FRANKLIN, 2005).

Numa analítica das estratégias da política da própria vida em biomedicina, Rose (2013) frisa que a política da vida em si mesma de nosso século não é delimitada simplesmente pelos polos de doença ou saúde, nem procura eliminar patologias para proteger o destino da nação. Nossa sociedade preocupa-se em controlar, administrar, projetar, remodelar e modular as próprias capacidades vitais dos seres humanos enquanto criaturas viventes, visando a fornecer segurança e bemestar. A acepção da vida em si mesma está no cerne do capitalismo biogenético, entendido como um regime que privilegia por investimentos financeiros em um mercado com potencial lucrativo (BRAIDOTTI, 2007). 
Durante o século XX, a consolidação da Psicologia enquanto campo de saber/poder teve grande impacto social nas concepções de normalidade e anormalidade, nas tecnologias de regulação, de consumo e normalização dos corpos (ROSE, 2008). Nesse período, vemos também a emergência de uma suposta descoberta do sujeito psicológico: um sujeito que nasce nos domínios do discurso científico ocidental moderno, ou melhor, que emerge como figura correlata desse discurso, considerando que "o sujeito psicológico" era uma figura inexistente na cultura ocidental, antes da dita emergência da cientificidade da Psicologia (PRADO FILHO; MARTINS, 2007).

A colocação da posição de sujeito nos domínios da Psicologia implica considerá-lo como objeto de um discurso científico socialmente autorizado a enunciar verdades a respeito das instâncias subjetivas. Enunciar o psicológico significa objetivar tudo aquilo que compõe o que denominamos: subjetividade, cognição, consciência, psiquismo, emoções, comportamentos, desejos; universalizando-os, socializando-os e naturalizando-os aos discursos cotidianos e aos modelos de vida (PRADO FILHO; MARTINS, 2007; ROSE, 2008). Como aponta Rose (2008), a Psicologia se forma, enquanto disciplina, em locais práticos onde problemas de condutas coletiva e individual passam a ser alvo de responsabilidades de autoridades as quais procuram controlá-las. Os vetores do desenvolvimento da Psicologia não se dão do normal para o anormal, mas de um conhecimento da normalidade derivado de um interesse na anormalidade, com o intuito de modular indivíduos com desejos e aspirações particulares em determinados espaços e lugares (ROSE, 2008; ROSE, 2011a).

O gerenciamento da saúde e da vitalidade é direcionado para "[...] a saúde biológica futura daqueles que nos levarão adiante para o futuro - nossos filhos e suas próprias vidas sadias" (ROSE, 2013, p. 356). Além do lucro, outros dois imperativos regem a economia, ou bioeconomia, atual: futuro e esperança. O futuro é considerado um objeto em construção; moldar e garantir o futuro requer a mobilização de técnicas, retóricas, recursos, materiais e tecnologias médicas constituem formas de regulação dos corpos.

A esperança envolve a interação entre o presente e o futuro, uma vez que ter esperança significa realizar ações direcionadas à construção de possíveis futuros desejáveis. A esperança estrutura a vida das pessoas, objetivando um futuro melhor. Ela é individual e coletiva, dado que permite a união de biografias individuais com interesses coletivos, processos sociais, econômicos e políticos (NOVAS, 2006). A precaução ganha mercado como compra e venda de seguros, frente aos riscos de viver com saúde e ter longevidade com a chamada qualidade de vida, além de poder circular pela cidade para nela e por ela realizar investimentos como empreendimento.

A tendência em melhorar a saúde e reformatar o corpo humano não é ineditismo das biotecnologias atuais. Como aponta Rose (2013), os seres humanos, na maior parte dos lugares, tentam incrementar seus si mesmos corporais, por meio de orações, meditações, dietas, fórmulas encantatórias, exercícios físicos e espirituais, almejando aumentar a saúde e a longevidade.

Do mesmo modo, a politização da vida não é algo recente. Foucault (2008b), no livro Nascimento da Biopolítica, aponta que, desde o século XVIII, o Estado intervém sobre a própria vida, em todos os seus âmbitos, criando mecanismos e medidas regulatórias de higienização, salubridade e saúde da população. A saúde passa a ser vinculada ao controle das cidades e dos corpos pelas mesmas, em regulações policiais sanitárias cada vez mais investidas como mercado da vida.

Se antes éramos considerados pacientes que recebíamos medidas médicas para curar patologias, controlar desvios indesejáveis do corpo ou promover estratégias biopolíticas de regulação dos corpos, através da modificação do estilo de vida, hoje, mais do que pacientes, nós nos tornamos também consumidores das intervenções médicas especializadas, temos acessos aos mais variados tipos de terapêuticas e podemos escolher e usá-las ativamente.

As pessoas estão sendo instadas a assumir a responsabilidade em relação a seu futuro médico e ao de seus filhos e famílias; e, na medida em que começam a vivenciar suas vidas em termos biomédicos, suas subjetividades estão sendo moldadas por aconselhamentos, novas linguagens, para descrever sua saúde e novos critérios para calcular os perigos e riscos (ROSE, 2011b).

Para ampliar o debate sobre a capitalização da vida, discorremos sobre o desenvolvimento de uma biopolítica centrada na regulação e normalização dos corpos e da saúde e o acúmulo de capital biológico. $\mathrm{O}$ poder e suas resistências têm como mesmo objeto/objetivo a vida. O direito à vida, ao corpo, à saúde, à felicidade e à satisfação das necessidades constitui o alvo da biopolítica. Mas, quando o poder exerce seu direito de matar em nome da existência de todos, as forças que se opõem a ele reclamam seu direito sobre a vida (FOUCAULT, 1888, 2005; GARCÉS, 2005).

Atualmente, o poder penetrou em todas as esferas da existência humana: desde os genes, o corpo, a afetividade, o psiquismo até a inteligência, a imaginação e a criatividade. Nossa vida está submetida aos mecanismos de modulação da existência, por isso, nossa dificuldade em resistir, pois o poder nunca chegou tão longe no cerne da subjetividade e da própria vida, em nome da vida e não do extermínio, nos pequenos e corriqueiros procedimentos de saúde. Já não sabemos “[...] onde está o poder e onde estamos nós, o que ele nos dita e o que queremos" (PELBART, 2008, p. 01).

Em outras palavras, as biopolíticas formam um conjunto de estratégias de regulação da vida, tendo como alvo os corpos das populações, objetivando produzir mais vidas, mais saúde, expressas em uma multiplicidade de dados estatísticos, médias e índices (PRADO FILHO, 2010). Os corpos são cada vez mais avaliados pela bioinformática e por suas performances diagnosticadas, pensadas medicamente e produtivamente, nos circuitos das cidades reguladas pela biopolítica. 
Foucault (2005), no livro Em defesa da sociedade, aponta três princípios ou três pontos a partir dos quais se constitui a biopolítica: 1) a noção de população - a biopolítica lida com um corpo múltiplo, com inúmeras cabeças; a população como problema político, econômico, científico e social; 2) a natureza dos fenômenos - a biopolítica vai se dirigir a fenômenos coletivos e que só aparecem com seus efeitos econômicos e políticos; e 3) os mecanismos implantados pela biopolítica são de medidas regulatórias - trata-se de estabelecer previsões, estimativas estatísticas para criar estratégias de regulação a uma dada população, com o intuito de otimizar a vitalidade.

Dessa maneira, as estratégias e as contestações de gestão da vida se preocupavam com problemas inerentes à vida, em sua dimensão coletiva e individual, considerando as formas de conhecimento, os regimes de autoridade e as práticas de intervenção que são desejáveis, legítimas e eficazes. Os dispositivos biopolíticos nascem no momento em que o Estado leva em consideração a questão de como se devem governar as pessoas, os bens, as riquezas; quais estratégias devem ser criadas, para que um bom pai saiba fazer prosperar sua família (LAZZARATO, 2000). O liberalismo, nesta época, passa a ser fundamental para o desenvolvimento de uma biopolítica e do capitalismo (FOUCAULT, 2008a).

No liberalismo, o governo assume a característica de uma tecnologia humana que gere a conduta dos outros; governar é agir sobre as pessoas que devem ser consideradas como livres. O liberalismo constituise, portanto, como uma arte de governar que assume o mercado como instrumento de inteligibilidade, verdade e medida da sociedade (LAZZARATO, 2013). No liberalismo, o biopoder e a biopolítica são mobilizados em termos de, por exemplo, planejamento e gestão de saúde e da cidade, enfocando higiene, alimentação, controle de natalidade e regulação da sexualidade (CASTIEL, 2010).

A preocupação política com a vida, mais especificamente, com a relação dos seres humanos e os problemas ligados ao seu meio de existência, a qual aparece no final do século XVIII e início do século XIX (FOUCAULT, 2005), articulada com o desenvolvimento de medidas eficazes dos métodos biotecnológicos destinados à manipulação do corpo em seu nível molecular, durante o século XX, fez com que os corpos e seus fragmentos passassem a ser comercializados por uma variedade de empresas, em Medicina Regenerativa e personalizada. Foucault (2008b), em Nascimento da Biopolítica, já apontava que os desenvolvimentos em genética constituíam um capital humano genético, fonte de renda humana direcionada para o futuro:

De fato, a genética atual mostra muito bem que um número de elementos muito mais considerável do que se pode imaginar até hoje [é] condicionado pelo equipamento genético que recebemos dos nossos ascendentes. Ela possibilita, em particular, estabelecer para um indivíduo dado, qualquer que seja ele, as probabilidades de contrair este ou aquele tipo de doença, numa idade dada, num período dado da vida ou de uma maneira totalmente banal num momento qualquer da vida. Em outras palavras, um dos interesses atuais da aplicação da genética às populações humanas é possibilitar reconhecer os indivíduos de risco e o tipo de risco que os indivíduos correm ao longo da sua existência. (FOUCAULT, 2008b, p. 313).

As primeiras áreas de intervenção, de saber e de poder da biopolítica foram: as taxas de natalidade, de mortalidade, das incapacidades biológicas diversas, dos efeitos do meio (FOUCAULT, 1988, 2005, 2008a). Medidas de regulação foram criadas para instruir as pessoas quanto ao cuidado com seus corpos, desde higiene básica até estratégias para controlar as doenças, em termos de governo da vida (ORTEGA, 2004; ROSE, 2011b). A biopolítica, na medida em que possibilita visualizar as complexidades dos campos empíricos, alerta-nos para as tramas em que a vida e o poder podem ser enredados.

A política e a ciência se cruzam com diferentes modelos regionais de saúde, e diversos grupos sociais têm sido mobilizados a apoiar e a apostar nos desenvolvimentos biomédicos. Essa mobilização tem um lugar cada vez mais no contexto de um mercado globalizado, onde o conhecimento e a competição para o controle futuro da economia geram formas de biopolíticas que sucumbem às exigências da competição mercadológica global e, ao mesmo tempo, estão susceptíveis às regulações políticas nacionais (SALTER; WALDBY, 2011).

Com as pesquisas biológicas básicas e aplicadas desenvolvidas em companhias de biotecnologias e em universidades, as biomedicinas estão cada vez mais ligadas à geração de propriedade intelectual e de valores para os acionistas. A saúde e a doença, por sua vez, emergem como campos férteis para a rentabilidade das corporações. Nessa lógica, a própria Medicina está se transformando: além de ser fragmentada em uma complexa divisão do trabalho entre especialistas, tornouse intensamente capitalizada (ROSE, 2011b). Introduzse, portanto, uma biomedicina que visa à centralização das informações e à normalização dos corpos e dos saberes, de sorte a adquirir igualmente o aspecto de medicalização da população.

A biomedicina configura-se como um "[...] saber/ poder que incide ao mesmo tempo sobre o corpo e sobre a população, sobre o organismo e sobre os processos biológicos" (FOUCAULT, 2005, p. 302), e que apresenta, com isso, medidas disciplinares no sentido de controlar e vigiar corpos individuais e efeitos regulamentares sobre a população.

A biomedicina, aliada às técnicas da Engenharia Tecidual, permite atividades clínicas propedêuticas médicas voltadas para o diagnóstico, tratamento, assistência e prevenção de doenças, além de orientação a possíveis patologias através de testes genéticos preditivos. A Medicina preditiva reporta, sobretudo, ao estudo genético de indivíduos sadios para identificar genes mutantes que predisponham a determinadas doenças de instalação na vida adulta. Esse tipo de Medicina introduz uma forma de prevenção à doença no formato de probabilidades futurológicas, por meio de técnicas da genética molecular (LLERENA JÚNIOR, 2000). 
Assistimos ao surgimento de uma nova governamentalidade, caracterizada pela regulação e vigilância da vida em si mesma em sua dimensão genômica. Nessa forma de governo, a subjetividade é reduzida a uma noção de corpo natureza biológica, que, por sua vez, é manipulado pela genética. Natureza-BiologiaGenética, uma sequência movida por um comércio que se legitima em nome da saúde pública e regulada pelo Estado e empresas privadas (FRANKLIN, 2000).

Ao discorrer sobre a politização e a tecnologização da "própria vida", Franklin (2000) resume os sentimentos que nos assolam, com os recentes desenvolvimentos das biotécnicas em relação a nossa vitalidade. Para a autora, nossa relação com as biotecnologias é caracterizada como um encontro ambivalente: se, de um lado, nós nos sentimos desconfortáveis, ao percebermos que as compreensões fundacionais do ser humano, o corpo, nossa vitalidade e nosso futuro estão sendo transformados; de outro, estamos propensos a interpretar os serviços ofertados pela biotecnologia como nostalgia pela passagem de certezas pré-estabelecidas, assim que recebemos a notícia de alguma técnica nova, criada ou melhorada.

Castiel (1994) também mostra que um sentimento difuso, o qual mescla fascínio e desconfiança em relação às práticas biotecnológicas em Genética molecular, está, cada vez mais, presente no cotidiano das camadas médias, no Brasil. O mercado que tende a abrir-se para parcerias internacionais permite que empresas transnacionais exerçam influência nas políticas de desenvolvimento dos países em que instalaram suas filiais. No Brasil, esse modelo de mercado tem sua origem no final dos anos 1980, quando medidas de modernização do Estado visavam a duas estratégias específicas: a abertura do mercado para transações multinacionais e a privatização de empresas públicas (CERVO, 1997).

Esse cenário se desenvolve a partir de políticas de cunho neoliberal, assinaladas pela globalização financeira, na qual investimentos estrangeiros dos denominados países desenvolvidos são realizados em países considerados periféricos, assim como pela reestruturação produtiva de grandes empresas, através da utilização de tecnologias da informação (WOLFF, 2014).

Tais estratégias de regulação da economia de mercado brasileiro têm mostrado o modo como nós somos governados hoje. No setor das biotecnologias, o Brasil tem sido considerado um mercado em potencial na América Latina, devido principalmente à biodiversidade que possuímos (BRASIL, 2000). Muitas cidades ganham, pela produção de cartões postais, um adjetivo de paisagem turística pelo selo ambiental-ecológico, por exemplo, em função dos recursos chamados de naturais que possuem ao redor e em seu interior, como praias, parques, lagos, rios, montanhas, florestas, mangues, riqueza de fauna e flora, entre outros, que poderão culturalmente, economicamente, subjetivamente e politicamente ser associados ao mercado do turismo e da saúde.
Bem-estar e qualidade de vida se tornam insígnias das viagens e da busca de migrações e imigrações, em nome da saúde coletiva e mental, bem como pela procura de lugar de trabalho, estudo, lazer e acesso às oportunidades. Cidades empreendedoras e sujeitos empresários de si e dos outros se tornam mercado para inovar e desenvolver tecnologias, em especial, pelos processos de medicalização da educação e da sociedade, na atualidade. Com efeito, o espaço das cidades vem cada vez mais experimentando mutações da ordem medicalizada, em uma política econômica neoliberal. Subjetividades empresariais e precaucionarias emergem coexistentes às cidades limpas, saneadas, alvo dos negócios de turismo, lugar de consumo, investida por mercados imobiliários e da saúde.

\section{Considerações finais: o que estamos em vias de nos tornarmos? Questões às Psicologias}

A Psicologia tem se preocupado com questões da subjetividade e com o chamado meio/cultura/ ambiente, em que se desenvolvem posições de sujeito, proporcionando dispositivos de mensuração que transformam as capacidades humanas em informações sobre as quais se poderia calcular, a fim de regular os comportamentos e tentar prever seus efeitos em táticas de controle social. Nesse campo, Foucault (2008b) afirma que a regulação do dispositivo de segurança opera mais pelo ambientalismo e biologismo, associadamente, para fomentar o empresariamento da vida, em especial, em sociedades liberais, ou seja, em sociedades marcadas pelo estilo de vida baseado na liberdade com segurança como mercado-investimento.

Algumas práticas psicológicas, como, por exemplo, as de cunho cognitivo-comportamentais e de testagem psicométrica e projetiva, são usadas ainda hoje para domesticar e disciplinar corpos, transformando as condutas em traços manipuláveis a serem codificados em dados probabilísticos, os quais podem ser utilizados e gerenciados por escolas, por centros médicos, por empresas, pelo turismo, por asilos, por fármacos e prisões (ROSE, 2011a).

Considerando os processos de subjetivação constituídos por diversas linhas, podemos afirmar que as maneiras como nos subjetivamos estão cada vez mais atravessadas por medicalizações da cidade e dos corpos, por meio de uma variedade de biotecnologias. Dessa maneira, aspectos que seriam tradicionalmente endereçados a outras áreas de saber passam igualmente a trazer questões que interessam à Psicologia, interrogando os modos de subjetivação que pautam a constituição do sujeito psicológico, no contemporâneo. Referimonos, por tecnologias biomédicas, aos ajuntamentos de dispositivos, instrumentos, matérias, técnicas pessoas que possibilitam agir sobre a conduta das pessoas, individual e coletivamente, assim como às cidades, com o intuito de gerar lucros empresariais.

A Psicologia vem transformando a forma como nos relacionamos conosco mesmos, uma vez que passamos a entender que somos habitados por um espaço subjetivo, 
fonte de nossos desejos e problemas (ROSE, 2011a, 2008; MILLER; ROSE, 2012). Desde o século XIX e ao longo do século XX, a Psicologia vem sendo chamada a atuar como prática auxiliar, no controle dos efeitos das modulações bioquímicas.

Contemporaneamente, com a presença marcante das biotecnologias, resta saber em que medida a Psicologia se manterá como discurso de legitimação ou não dos dispositivos e técnicas que estão sendo desenvolvidos para o gerenciamento das vidas biológicas nas cidades e pelas mesmas, ao ponto de acompanharmos o surgimento de um biocapital sem precedentes.

Nesse aspecto, os processos de medicalização dos corpos e das cidades ganham importância e mercado profissional, tornam-se lucrativos e potenciais empreendimentos, em uma sociedade liberal; com efeito, no neoliberalismo, acirra-se essa lógica medicalizante das condutas e dos espaços como investimento da vida empresariada. Os estudos de Michel Foucault nos auxiliam a pensar historicamente essas práticas e seus efeitos, no presente, para que possamos tentar resistir a esses dispositivos de segurança modernos. O espaço medicalizado ganha maior lucratividade e gera a chamada qualidade de vida, ao ser padronizado por normas e leis produtoras de saúde e, portanto, mais valorizados e rentáveis para os negócios de corporações variadas.

\section{Referências}

BRAIDOTTI, R. Bio-power and Necro-politics. Springerin, Hefte fur Gegenwartskunst, Wien, v. 13, n. 2, p. 18-23, 2007. Disponível em: <http://www.springerin.at/dyn/heft_text. php?textid=1928\&lang=en>. Acesso em: 20 dez. 2014.

BRASIL. Ministério do Meio Ambiente. Convenção sobre diversidade biológica - CDB: Cópia do Decreto Legislativo $\mathrm{n}^{\circ} 2$, de 5 de junho de 1992. Brasília, DF: MMA, 2000. Disponível em: <http://www.mma.gov.br/estruturas/sbf chm rbbio/ arquivos/cdbport 72.pdf $>$. Acesso em: 19 ago. $\overline{2} 014$.

CASTIEL, C. Uma saúde pública molecular!? Cad. Saúde Pública, v. 10, n. 3, p. 285-319, 1994.

CASTIEL, C. Risco e hiperprevenção: o epidemiopoder e a promoção da saúde como prática biopolítica com formato religioso. In: NOGUEIRA, R. P. (Org.). Determinação social da saúde e da reforma sanitária. Rio de Janeiro: Cebes, 2010. p. 161-179.

CASTIEL, C. Saúde, riscos e hiperprevenção. Acta Paul Enferm, v. 24, n. 4, p. 34-35, 2011. Disponível em: <http:// www.redalyc.org/articulo.oa?id=307023874001>. Acesso em: 20 dez. 2014.

CERVO, A. L. Política de comércio exterior e desenvolvimento: a experiência brasileira. Rev. Bras. Polit. Int., v. 40, n. 2, p. 5-26, 1997.

CÉSAR, M. R. de A. (Des)educando corpos: volumes, comidas, desejos e a nova pedagogia alimentar. In: RAGO, M.; VEIGANETO, A. (Org.). Para uma vida não fascista. Belo Horizonte: Autêntica, 2009. p. 269-280.

MELHORES cidades para empreender, As. Exame, São Paulo, edição 1078, ano 48, n. 22, 26 nov. 2014.
FOUCAULT, M. Microfisica do poder. Petrópolis, RJ: Vozes, 1979.

FOUCAULT, M. História da Sexualidade: a vontade de saber. Rio de Janeiro: Graal, 1988. v. 1.

FOUCAUlT, M. Em defesa da Sociedade. São Paulo: Martins Fontes, 2005.

FOUCAULT, M. Segurança, território e população. São Paulo: Martins Fontes, 2008a.

FOUCAULT, M. Nascimento da Biopolítica. São Paulo: Martins Fontes, 2008b.

FRANKLIN, S. Life Itself: Global Nature and the Genetic Imaginary. In: FRANKLIN, S.; LURY, C.; STACEY, J. (Ed.). Global Nature, Global Culture. Londres: Sage, 2000. p. 188227.

FRANKLIN, S. Stem Cells R US: Emergent Life forms and the Global Biological. In: ONG, A.; COLLIER, S. J. (Ed.). Global Assemblages: Tecnology, Politics, and Ethics as Antropological problems. Malden, MA: Blackwell, 2005. p. 59-78.

GARCÉS, M. La vida como concepto político: una lectura de Foucault y Deleuze. Athenea Digital, [online], n. 7, p. 87-104, primavera 2005. Disponível em: <http://www.raco.cat/index. php/Athenea/article/viewFile/264157/351798>. Acesso em: 19 dez. 2014.

GÓMEZ, Z. P. El régimen biopolítico en América Latina: cuerpo y pensamiento social. Iberoamericana, v. IV, n. 15, p. 7-19, 2004.

JURASSIC Park. Direção: Steven Spielberg. USA: Universal Pictures: 1993. 1 DVD.

LAZZARATO, M. Du biopouvoir à la biopolitique. Multitudes: revue politique, artistique, philosophique, n. 1, p. 1-8, 2000.

LAZZARATO, M. Biopolítica/Bioeconomia. In: PASSOS, I. C. F. (Org.). Poder, normalização e violência: incursões foucaultianas para a atualidade. 2. ed. Belo Horizonte: Autêntica, 2013.

LLERENA JÚNIOR, J. C. A Genética Médica nas interfaces da ciência, ética e sociedade. In: CARNEIRO, F.; EMERICK, M. C. (Org.). Limite: a ética e o debate jurídico sobre acesso e uso do genoma humano. Rio de Janeiro: Fiocruz, 2000.

MILLER, P.; ROSE, N. Governando o presente: gerenciamento da vida econômica, social e pessoal. São Paulo: Paulus, 2012.

NOVAS, C. The political economy of hope: patients' organizations, Science and biovalue. BioSocieties, [online.], v. 1, p. 289-305, 2006. Disponível em: <http://dx.doi.org/10.1017/ S1745855206003024>. Acesso em: 20 dez. 2014.

ORTEGA, F. Biopolíticas da saúde: reflexões a partir de Michel Foucault, Agnes Heller e Hannah Arendt. Interface, Botucatu, v. 8, n. 14, p. 9-20, fev. 2004. Disponível em: <http:// Www.scielo.br/scielo.php?script=sci arttext\&pid=S1414$32832004000100002 \& \operatorname{lng}=\mathrm{en} \& \mathrm{nrm}=\mathrm{iso}>$. Acesso: em $20 \mathrm{dez}$. 2014.

ORTEGA, F. O corpo incerto: corporeidade, tecnologias médicas e cultura contemporânea. Rio de Janeiro: Garamond, 2008 .

PELBART, P.Vida e morte em contexto de dominaçãobiopolítica. In: O FUNDAMENTALISMO CONTEMPORÂNEO EM QUESTÃO, 2008. São Paulo. Anais... São Paulo: IEA/USP, 2008, p. 1-21. 
PRADO FILHO, K. Uma genealogia das práticas de normalização nas sociedades ocidentais modernas. In: CAPONI, S. et al. (Org.). Medicalização da Vida: Ética, Saúde Pública e Indústria Farmacêutica. Palhoça: Unisul, 2010. p. 183-191.

PRADO FILHO, K.; MARTINS, S. A subjetividade como objeto da(s) psicologia(s). Psicologia \& Sociedade, v. 19, n. 3, p. 14-19, 2007.

RABINOW, P. Antropologia da razão. Rio de Janeiro: Relume Dumará, 1999.

ROSE, N. Psicologia como uma ciência social. Psicologia \& Sociedade, Porto Alegre, v. 20, n. 2, p. 155-164, maio./ago. 2008.

ROSE, N. Inventando nossos selfs: Psicologia, poder e subjetividade. Petrópolis, RJ: Vozes, 2011a.

ROSE, N. Biopolítica molecular, ética somática e o espírito do biocapital. In: SANTOS, L. H. S.; RIBEIRO, P. R. C. (Org.). Corpo, gênero e sexualidade: instâncias e práticas de produção nas políticas da própria vida. Rio Grande: FURG, 2011b. p. 1332.

ROSE, N. A política da própria vida: biomedicina, poder e subjetividade no século XXI. São Paulo: Paulus, 2013.

SALTER, B.; WALDBY, C. Biopolitics in China: an introduction. East Asian Science, Technology and Society: An International Journal, v. 5, p. 287-290, 2011.

SANT'ANNA, D. B. Dietética e conhecimento de si. In: RAGO, M.; VEIGA-NETO, A. (Org.). Para uma vida não fascista. Belo Horizonte: Autêntica, 2009. p. 83-94.

WALDBY, C. Biomedicine, tissue transfer and Intercorporeality. Feminist Theory, [online], v. 3, n. 3, p. 239-254, 2002. Disponível em: <http://fty.sagepub.com/content/3/3/239.full. pdf>. Acesso em: 10 jan. 2015.

WOLFF, S. Desenvolvimento local, empreendedorismo e "governança" urbana: onde está o trabalho neste contexto? Caderno CRH, v. 27, n. 70, p. 131-150, 2014.

Recebido em: 27 de janeiro de 2015 Aceito em: 16 de fevereiro de 2016 